\title{
Structural position and oxidation state of nickel in $\mathrm{SrTiO}_{3}$
}

\author{
Irina A. Sluchinskaya* ${ }^{*}$, Alexander I. Lebedev* and Alexei Erko ${ }^{\dagger}$ \\ *Physics Department, Moscow State University \\ Leninskie gory, 119991 Moscow, Russia \\ ${ }^{\dagger}$ Helmholtz-Zentrum Berlin \\ Albert-Einstein-Str. 15, 12489 Berlin, Germany \\ Firinasluch@nm.ru
}

Received 19 July 2013; Revised 2 October 2013; Accepted 14 November 2013; Published 13 December 2013

\begin{abstract}
The properties of Ni-doped strontium titanate are studied using X-ray diffraction and XAFS spectroscopy. It is shown that regardless of the preparation conditions, the $\mathrm{SrTi}_{1-x} \mathrm{Ni}_{x} \mathrm{O}_{3}$ solid solution and the $\mathrm{NiTiO}_{3}$ phase are the most stable phases which can coexist. According to the EXAFS data, in the single-phase sample of $\mathrm{SrTi}_{0.97} \mathrm{Ni}_{0.03} \mathrm{O}_{3}$, the $\mathrm{Ni}$ atoms substitute for the Ti ones and are oncenter. The distortion of the oxygen octahedra is not observed. The XANES spectra analysis shows that the oxidation state of nickel in $\mathrm{NiTiO}_{3}$ is 2+, and in the $\mathrm{SrTi}_{1-x} \mathrm{Ni}_{x} \mathrm{O}_{3}$ solid solution it is close to 4+. It is shown that the strongest light absorption in doped samples is associated with the presence of tetravalent nickel in the $\operatorname{SrTi}_{1-x} \mathrm{Ni}_{x} \mathrm{O}_{3}$ solid solution. This doping seems the most promising one for solar energy converters that exploit the bulk photovoltaic effect.
\end{abstract}

Keywords: XAFS spectroscopy; impurities; strontium titanate; solar energy conversion.

\section{Introduction}

The bulk photovoltaic effect consists in the occurrence of a photocurrent and very large photovoltages when illuminating homogeneous crystals having no inversion symmetry. ${ }^{1}$ The idea of the practical application of this effect in ferroelectrics for solar energy conversion was discussed back in the $70 \mathrm{~s}^{2}$ However, because of the short lifetime of photo-excited carriers, the quantum yield of this effect is generally small, and the idea was decided to be unproductive. In recent years, the interest to the ferroelectric oxides with the perovskite structure has revived because new ideas on how to increase the efficiency of solar energy converters based on the bulk photovoltaic effect have been proposed. ${ }^{3,4}$ The main disadvantage of the ferroelectric oxides is their relatively large bandgap, causing them to absorb only a small fraction of the solar radiation. Recent theoretical studies have shown that the substitution of $\mathrm{Ti}$ atoms at the $B$ sites of the perovskite structure with divalent impurities having the $d^{8}$ electron configuration $(\mathrm{Ni}, \mathrm{Pd}, \mathrm{Pt})$, compensated by the oxygen vacancy, decreases the bandgap and the obtained perovskites are polar semiconductor oxides. ${ }^{5,6}$

An additional interest to the study of the Ni impurity is associated with the results obtained from the recent experimental and theoretical studies of new materials - a recently synthesized $\mathrm{PbNiO}_{3}$ which has a very high calculated spontaneous polarization ${ }^{7-9}$ and $\mathrm{BiNiO}_{3}$ with unexpected oxidation states of nickel and bismuth atoms. ${ }^{10}$

In addition, the search for new magnetic off-center impurities in incipient ferroelectrics is still important because they can result in simultaneous emergence of the ferroelectricity and magnetic ordering and give rise to the magnetoelectric interaction. Materials with these properties belong to multiferroics. $\mathrm{SrTiO}_{3}$ doped with $\mathrm{Mn}$ at the $A$ site is an example of such a material, in which a new type of magnetoelectric interaction was recently discovered. ${ }^{11,12} \mathrm{Ni}$-doped samples could be an another example.

Since the doping impurity can enter several different sites in the perovskite structure and stay in them in different oxidation states, the aim of this work was to study the structural position and the oxidation state of the Ni impurity in $\mathrm{SrTiO}_{3}$ prepared under different conditions using XAFS spectroscopy. We planned to check the possibility of preparing samples doped with divalent $\mathrm{Ni}$ at the $B$ site, to evaluate the possibility of incorporating the $\mathrm{Ni}$ impurity into the $A$ site, and to establish a correlation between the optical properties of the samples, on the one hand, and the structural position and the oxidation state of the Ni impurity, on the other hand. The choice of $\mathrm{SrTiO}_{3}$ was dictated by the fact that earlier we have studied the structural position and the oxidation state of a number of $3 d$ elements in $\mathrm{SrTiO}_{3}\left(\mathrm{Mn},{ }^{13,14} \mathrm{Co},{ }^{15} \mathrm{Fe}^{16}\right)$, and their combined analysis can allow to find new promising impurities for solar energy converters.

\section{Samples and Experimental Techniques}

Ni-doped samples of $\mathrm{SrTiO}_{3}$ with the impurity concentration of $2-3 \%$ and different deviation from stoichiometry were prepared by the solid-state reaction method. The starting materials were $\mathrm{SrCO}_{3}$, nanocrystalline $\mathrm{TiO}_{2}$, and $\mathrm{Ni}$ $\left(\mathrm{CH}_{3} \mathrm{COO}\right)_{2} \cdot 4 \mathrm{H}_{2} \mathrm{O}$. The components were weighed in proper proportions, mixed, ground in acetone, and calcined in air at $1100^{\circ} \mathrm{C}$ for $8 \mathrm{~h}$. The calcined powders were ground once 
more and annealed again under the same conditions. Some of the samples were additionally calcined in air at $1500^{\circ} \mathrm{C}$ for $2 \mathrm{~h}$. The composition of the samples was deliberately deviated from stoichiometry (excess titanium or excess strontium) in order to incorporate the impurity into the $A$ or $B$ site of the perovskite structure.

The reference compounds $\mathrm{NiO}, \mathrm{NiTiO}_{3}$, and $\mathrm{BaNiO}_{3-\delta}$ used for determination of the oxidation state of $\mathrm{Ni}$ in $\mathrm{SrTiO}_{3}$ were prepared as follows. $\mathrm{NiO}$ was obtained by thermal decomposition of $\mathrm{Ni}\left(\mathrm{CH}_{3} \mathrm{COO}\right)_{2} \cdot 4 \mathrm{H}_{2} \mathrm{O}$. Two other samples were prepared by the solid-state reaction method in air: the $\mathrm{NiTiO}_{3}$ sample was obtained from $\mathrm{Ni}\left(\mathrm{CH}_{3} \mathrm{COO}\right)_{2} \cdot 4 \mathrm{H}_{2} \mathrm{O}$ and $\mathrm{TiO}_{2}$ at $1100^{\circ} \mathrm{C}$, the $\mathrm{BaNiO}_{3-\delta}$ sample was prepared from $\mathrm{BaO}_{2}$ and $\mathrm{NiO}$ at $650^{\circ} \mathrm{C}$. The phase composition of the samples was controlled by X-ray diffraction.

Extended X-ray absorption fine structure (EXAFS) and $\mathrm{X}$-ray absorption near-edge structure (XANES) spectra were obtained at KMC-2 station of the BESSY synchrotron radiation source (the beam energy $1.7 \mathrm{GeV}$; the beam current up to $290 \mathrm{~mA})$ at the $\mathrm{Ni} K$-edge $(8340 \mathrm{eV})$ at $300 \mathrm{~K}$. The radiation was monochromatized by a double-crystal $\mathrm{Si}_{1-x} \mathrm{Ge}_{x}(111)$ monochromator. Spectra were collected in fluorescence mode. The radiation intensity incident on the sample $\left(I_{0}\right)$ was measured by an ionization chamber; the fluorescence intensity $\left(I_{f}\right)$ was measured by a silicon energydispersive RÖNTEC X-flash detector with $10 \mathrm{~mm}^{2}$ active area.

Isolation of the oscillating EXAFS function $\chi(k)$ from the fluorescence excitation spectra $\mu(E)=I_{f} / I_{0}$ (where $E$ is the X-ray photon energy) was performed in the traditional way. ${ }^{17,18}$ After subtracting the pre-edge background, splines were used to extract the monotonic atomic part of the spectrum $\mu_{0}(E)$ and then the dependence of $\chi=\left(\mu-\mu_{0}\right) / \mu_{0}$ was calculated as a function of the photoelectron wave vector $k=\left(2 m\left(E-E_{0}\right) / \hbar^{2}\right)^{1 / 2}$. The energy origin, $E_{0}$, was taken to be the position of the inflection point on the absorption edge. For each sample three spectra were recorded, they were then independently processed, and the resulting $\chi(k)$ curves finally averaged.

Direct and inverse Fourier transforms with modified Hanning windows were used to extract the information about the first three shells from the obtained $\chi(k)$ curves. The distances $R_{j}$ and Debye-Waller factors $\sigma_{j}^{2}$ for $j$ th shell $(j=1-$ $3)$ as well as the energy origin correction $d E_{0}$ were simultaneously varied to obtain the minimum root-mean-square deviation between the experimental and calculated $k^{2} \chi(k)$ curves. The coordination numbers were considered fixed for a given structural model. The number of adjustable parameters (8) was usually about a half of the number of independent data points $N_{\text {ind }}=2 \Delta k \Delta R / \pi \approx 16$.

The single- and multiple-scattering amplitudes and phase shifts, the central atom phase shift, and the photoelectron mean free path as a function of $k$, needed to calculate the theoretical curves $\chi(k)$, were computed using the FEFF6 software. $^{19}$
EXAFS spectra were also analyzed with a widely used IFEFFIT software package. ${ }^{20}$ Isolation of the experimental EXAFS function was carried out using the ATHENA program and its fitting to the theoretical curve calculated for a given structural model was performed using the ARTEMIS program. In this approach, the amplitudes and phase shifts for all single- and multiple-scattering paths were also calculated using the FEFF6 software. The results obtained by two different data analysis approaches agreed well.

\section{Results}

\subsection{X-ray data}

The diffraction patterns of all investigated samples are shown in Fig. 1. It is seen that the $\mathrm{SrTi}_{0.97} \mathrm{Ni}_{0.03} \mathrm{O}_{3}$ sample annealed at $1500^{\circ} \mathrm{C}$ is the only single-phase sample which has a cubic perovskite structure; for other samples, additional reflections were observed on the diffraction patterns. For the $\mathrm{SrTi}_{0.97} \mathrm{Ni}_{0.03} \mathrm{O}_{3}$ and $\mathrm{Sr}_{0.98} \mathrm{Ni}_{0.02} \mathrm{TiO}_{3}$ samples annealed at $1100^{\circ} \mathrm{C}$, along with the reflections characteristic of the perovskite phase, additional reflections indicating a small amount of $\mathrm{TiO}_{2}$ and, presumably, $\mathrm{NiTiO}_{3}$ were observed. The identification of a possible $\mathrm{NiO}$ phase was complicated by the closeness of its reflections to the position of $\mathrm{NiTiO}_{3}$ reflections. In addition, stronger lines of the Ruddlesden-Popper phases $\mathrm{Sr}_{3} \mathrm{Ti}_{2} \mathrm{O}_{7}$ and $\mathrm{Sr}_{4} \mathrm{Ti}_{3} \mathrm{O}_{10}$ were observed in the $\mathrm{SrTi}_{0.97}$ $\mathrm{Ni}_{0.03} \mathrm{O}_{3}$ sample annealed at $1100^{\circ} \mathrm{C}$. In the $\mathrm{Sr}_{0.98} \mathrm{Ni}_{0.02} \mathrm{TiO}_{3}$ sample annealed at $1500^{\circ} \mathrm{C}$ the only additional phase, $\mathrm{NiTiO}_{3}$, was found.

Since barium nickelate $\mathrm{BaNiO}_{3-\delta}$ is a defective phase with the $\delta$ value depending on the preparation conditions, its lattice parameters dependence on the $\delta$ value $^{21}$ was used to determine the actual oxygen content in our $\mathrm{BaNiO}_{3-\delta}$

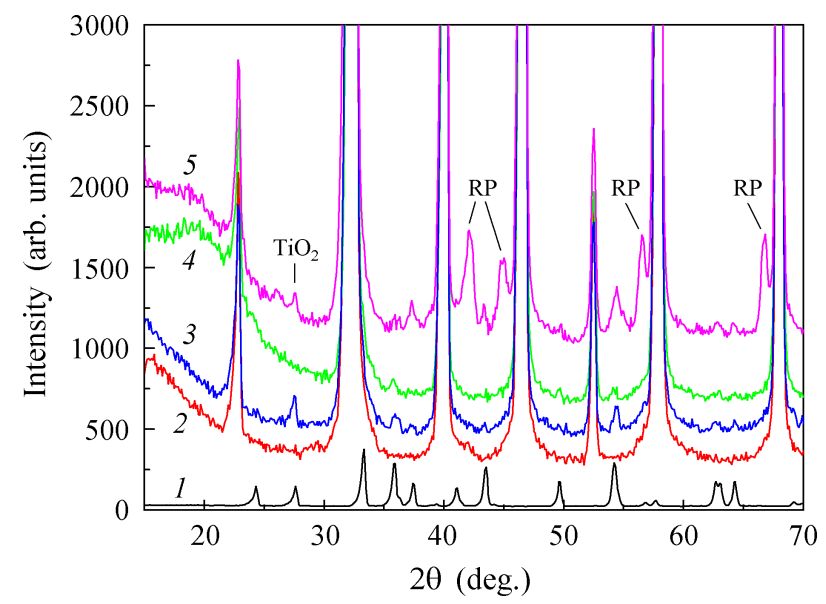

Fig. 1. (Color online) Diffraction patterns of samples: (1) $\mathrm{NiTiO}_{3}$, (2) $\mathrm{SrTi}_{0.97} \mathrm{Ni}_{0.03} \mathrm{O}_{3}$ sample annealed at $1500^{\circ} \mathrm{C}$, (3) $\mathrm{Sr}_{0.98} \mathrm{Ni}_{0.02} \mathrm{TiO}_{3}$ sample annealed at $1100^{\circ} \mathrm{C}$, (4) $\mathrm{Sr}_{0.98} \mathrm{Ni}_{0.02} \mathrm{TiO}_{3}$ sample annealed at $1500^{\circ} \mathrm{C}$, and (5) $\mathrm{SrTi}_{0.97} \mathrm{Ni}_{0.03} \mathrm{O}_{3}$ sample annealed at $1100^{\circ} \mathrm{C}$. Reflections of $\mathrm{TiO}_{2}$ and Ruddlesden-Popper (RP) phases are also indicated. 


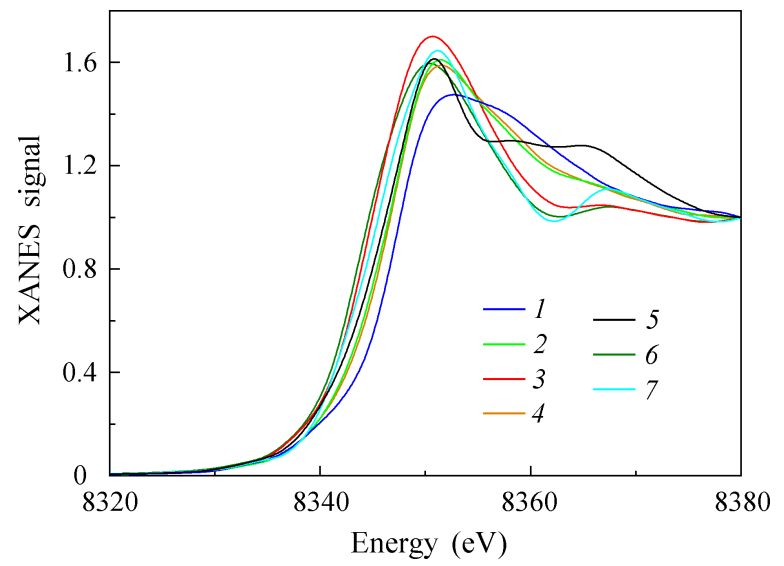

Fig. 2. (Color online) XANES spectra for $\mathrm{SrTiO}_{3}(\mathrm{Ni})$ samples and nickel reference compounds: (1) $\mathrm{SrTi}_{0.97} \mathrm{Ni}_{0.03} \mathrm{O}_{3}$ sample annealed at $1500^{\circ} \mathrm{C}$, (2) $\mathrm{SrTi}_{0.97} \mathrm{Ni}_{0.03} \mathrm{O}_{3}$ sample annealed at $1100^{\circ} \mathrm{C}$, (3) $\mathrm{Sr}_{0.98} \mathrm{Ni}_{0.02} \mathrm{TiO}_{3}$ sample annealed at $1500^{\circ} \mathrm{C}$, (4) $\mathrm{Sr}_{0.98} \mathrm{Ni}_{0.02} \mathrm{TiO}_{3}$ sample annealed at $1100^{\circ} \mathrm{C}$, (5) $\mathrm{BaNiO}_{3-\delta}$, (6) $\mathrm{NiTiO}_{3}$ and (7) $\mathrm{NiO}$.

sample. The hexagonal lattice parameters of $a=5.568 \pm$ $0.001 \AA, c=4.838 \pm 0.001 \AA$ in our sample correspond to $\delta \approx 0.4$.

\subsection{XANES data analysis}

To determine the oxidation state of the Ni impurity in $\mathrm{SrTiO}_{3}$, the position of the absorption edge in XANES spectra of the samples was compared with the edge positions in the reference compounds. XANES spectra of all studied samples and three reference compounds are shown in Fig. 2.

Comparison of the spectra of the $\mathrm{Sr}_{0.98} \mathrm{Ni}_{0.02} \mathrm{TiO}_{3}$ sample annealed at $1500^{\circ} \mathrm{C}$ with the spectra of cubic $\mathrm{NiO}$ and rhombohedral $\mathrm{NiTiO}_{3}$ (with the ilmenite structure) shows that the absorption edges in these samples are very close. So, we conclude that the Ni impurity in the sample under consideration is in the $2+$ oxidation state. The absorption edges of the $\mathrm{SrTi}_{0.97} \mathrm{Ni}_{0.03} \mathrm{O}_{3}$ and $\mathrm{Sr}_{0.98} \mathrm{Ni}_{0.02} \mathrm{TiO}_{3}$ samples annealed at $1100^{\circ} \mathrm{C}$ are close to the absorption edge of the $\mathrm{BaNiO}_{3-\delta}$ reference compound. In the single-phase $\operatorname{SrTi}_{0.97} \mathrm{Ni}_{0.03} \mathrm{O}_{3}$ sample annealed at $1500^{\circ} \mathrm{C}$, the absorption edge is shifted to even higher energies (by $2.5 \mathrm{eV}$ as compared to $\mathrm{NiO}$, by $2.9 \mathrm{eV}$ as compared to $\mathrm{NiTiO}_{3}$, and by $1.3 \mathrm{eV}$ as compared to $\mathrm{BaNiO}_{3-\delta}$ ).

\subsection{EXAFS data analysis}

To determine the structural position of the $\mathrm{Ni}$ impurity, EXAFS spectra were analyzed. A typical EXAFS spectrum $k^{2} \chi(k)$ for the single-phase $\operatorname{SrTi}_{0.97} \mathrm{Ni}_{0.03} \mathrm{O}_{3}$ sample annealed at $1500^{\circ} \mathrm{C}$ and its best theoretical fit (which takes into account the multiple-scattering effects) are shown in Fig. 3.

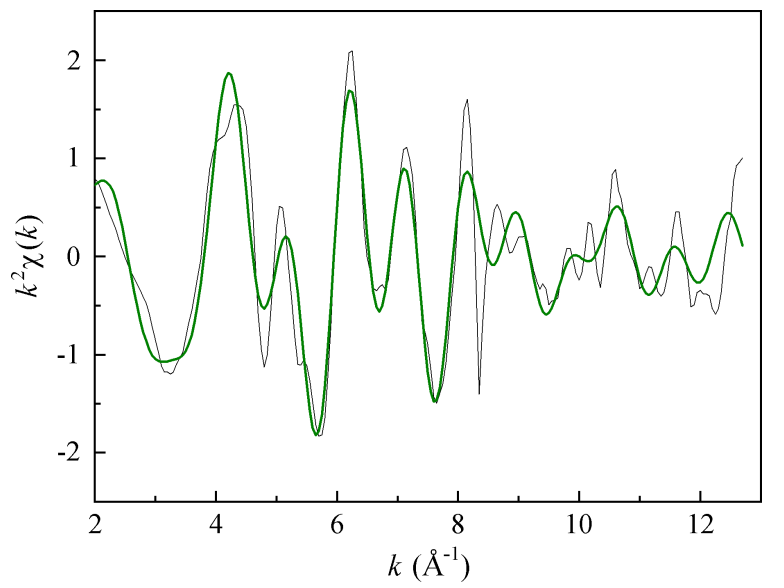

Fig. 3. (Color online) EXAFS spectrum recorded at the Ni $K$-edge at $300 \mathrm{~K}$ for $\mathrm{SrTi}_{0.97} \mathrm{Ni}_{0.03} \mathrm{O}_{3}$ sample annealed at $1500^{\circ} \mathrm{C}$ (thin black line) and its best theoretical fit (thick green line).

The best agreement between the calculated and experimental data was obtained in the model in which $\mathrm{Ni}$ atoms substitute for $\mathrm{Ti}$ atoms in $\mathrm{SrTiO}_{3}$. The interatomic distances and Debye-Waller factors for three nearest shells are given in Table 1. Small values of the Debye-Waller factor for the first and second shells, which are typical for the thermal vibrations in perovskites at $300 \mathrm{~K}$, enable to draw two conclusions: (1) the off-centering of Ni atoms at the $B$ sites can be excluded and (2) there is no distortion of the oxygen octahedra around the impurity atoms. ${ }^{\mathrm{a}}$

The analysis of the EXAFS spectra helped us to determine the composition of the second phase precipitating in the $\mathrm{Sr}_{0.98} \mathrm{Ni}_{0.02} \mathrm{TiO}_{3}$ sample annealed at $1500^{\circ} \mathrm{C}$. Although the distances and the coordination numbers for the first shell of $\mathrm{Ni}$ are close in $\mathrm{NiO}$ and $\mathrm{NiTiO}_{3}$, the coordination numbers for the second shell in these compounds differ by three times. A comparison of the Fourier transforms of the EXAFS spectra for the sample under consideration and two reference compounds, $\mathrm{NiTiO}_{3}$ and $\mathrm{NiO}$, shows a better agreement of its spectrum with that of $\mathrm{NiTiO}_{3}$ (Fig. 4). This means that among two possible phases, $\mathrm{NiTiO}_{3}$ and $\mathrm{NiO}$, the second phase in our samples is the $\mathrm{NiTiO}_{3}$ one.

As concerns to two-phase $\mathrm{SrTi}_{0.97} \mathrm{Ni}_{0.03} \mathrm{O}_{3}$ and $\mathrm{Sr}_{0.98}$ $\mathrm{Ni}_{0.02} \mathrm{TiO}_{3}$ samples annealed at $1100^{\circ} \mathrm{C}$, the comparison of their EXAFS spectra with the EXAFS spectrum of the single-phase solid solution and the EXAFS spectrum of $\mathrm{NiTiO}_{3}$ shows that the spectra of the samples under discussion may be represented as a superposition of the spectra of $\mathrm{NiTiO}_{3}$ and of the solid solution in a ratio close to $1: 1$.

The optical properties of the samples are consistent with the data obtained above. The $\mathrm{Sr}_{0.98} \mathrm{Ni}_{0.02} \mathrm{TiO}_{3}$ sample

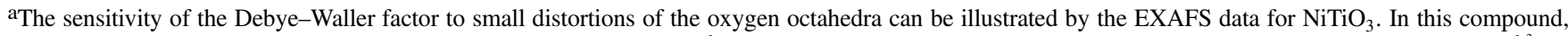
there are two Ni-O distances in the first shell which differ by $\sim 0.07 \AA$; such a small distortion increases the Debye-Waller factor to $0.0073 \pm 0.0012 \AA^{2}$. 
Table 1. Structural parameters obtained from the data analysis of the EXAFS spectra for $\mathrm{SrTi}_{0.97} \mathrm{Ni}_{0.03} \mathrm{O}_{3}$ sample annealed at $1500^{\circ} \mathrm{C}\left(R_{i}\right.$ is the distance to the $i$ th shell, $\sigma_{i}^{2}$ is the Debye-Waller factor for this shell).

\begin{tabular}{cccc}
\hline Shell & $R_{i}(\AA)$ & $\sigma_{i}^{2}\left(\AA^{2}\right)$ & Atom \\
\hline 1 & $1.914 \pm 0.004$ & $0.0035 \pm 0.0006$ & $\mathrm{O}$ \\
2 & $3.342 \pm 0.006$ & $0.0084 \pm 0.0007$ & $\mathrm{Sr}$ \\
3 & $3.877 \pm 0.004$ & $0.0053 \pm 0.0005$ & $\mathrm{Ti}$ \\
\hline
\end{tabular}

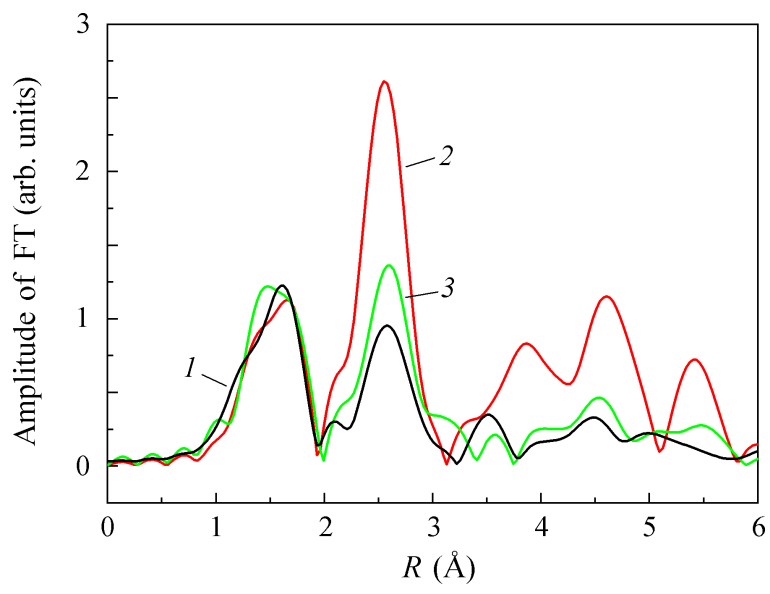

Fig. 4. (Color online) Comparison of Fourier transforms of the EXAFS $k^{2} \chi(k)$ spectra obtained for (1) $\mathrm{Sr}_{0.98} \mathrm{Ni}_{0.02} \mathrm{TiO}_{3}$ sample annealed at $1500^{\circ} \mathrm{C}$ and for (2) $\mathrm{NiO}$ and (3) $\mathrm{NiTiO}_{3}$ reference compounds.

annealed at $1500^{\circ} \mathrm{C}$ had a light brown color; the $\mathrm{SrTi}_{0.97} \mathrm{Ni}_{0.03} \mathrm{O}_{3}$ and $\mathrm{Sr}_{0.98} \mathrm{Ni}_{0.02} \mathrm{TiO}_{3}$ samples annealed at $1100^{\circ} \mathrm{C}$ were dark brown; the $\mathrm{SrTi}_{0.97} \mathrm{Ni}_{0.03} \mathrm{O}_{3}$ sample annealed at $1500^{\circ} \mathrm{C}$ had an almost black color. Thus, the color of the samples reflects the relative amounts of black $\mathrm{SrTi}_{1-x} \mathrm{Ni}_{x} \mathrm{O}_{3}$ and yellow $\mathrm{NiTiO}_{3}$ phases in the samples.

\section{Discussion}

Combined analysis of X-ray and EXAFS data shows that the $\mathrm{SrTi}_{0.97} \mathrm{Ni}_{0.03} \mathrm{O}_{3}$ sample annealed at $1500^{\circ} \mathrm{C}$ is the singlephase solid solution in which the $\mathrm{Ni}$ atoms substitute for the Ti atoms at the $B$ sites and are on-center. This means that the solubility of nickel at the $B$ sites in $\mathrm{SrTiO}_{3}$ exceeds $3 \%$ at $1500^{\circ} \mathrm{C}$. In the sample with a nominal composition of $\mathrm{SrTi}_{0.97} \mathrm{Ni}_{0.03} \mathrm{O}_{3}$ annealed at $1100^{\circ} \mathrm{C}$, the appearance of reflections of $\mathrm{NiTiO}_{3}$ and of the Ruddlesden-Popper phases indicates that a part of $\mathrm{Ni}$ atoms is spent on the $\mathrm{NiTiO}_{3}$ formation, while the other part remains at the $B$ sites. As a result, some untapped $\mathrm{Sr}$ atoms form the $\mathrm{SrO}$ planes which embed into the perovskite structure and form the $\mathrm{Sr}_{3} \mathrm{Ti}_{2} \mathrm{O}_{7}$ and $\mathrm{Sr}_{4} \mathrm{Ti}_{3} \mathrm{O}_{10}$ phases.

When trying to incorporate $\mathrm{Ni}$ atoms into the $A$ sites of $\mathrm{SrTiO}_{3}$ at $1500^{\circ} \mathrm{C}$ (the samples with a nominal composition of $\mathrm{Sr}_{0.98} \mathrm{Ni}_{0.02} \mathrm{TiO}_{3}$ ), the precipitation of the $\mathrm{NiTiO}_{3}$ second phase occurs. The concentration of nickel in the solid solution phase is small, as it follows from the EXAFS data and the sample color. In contrast, when annealing the $\mathrm{Sr}_{0.98} \mathrm{Ni}_{0.02} \mathrm{TiO}_{3}$ sample at a lower temperature $\left(1100^{\circ} \mathrm{C}\right)$, nickel in the sample is in a mixture of $\mathrm{NiTiO}_{3}$ and $\mathrm{SrTi}_{1-x} \mathrm{Ni}_{x} \mathrm{O}_{3}$ solid solution as follows from the XANES data, EXAFS data, and the sample color. The precipitation of a small portion of $\mathrm{TiO}_{2}$ confirms the incorporation of $\mathrm{Ni}$ into $\mathrm{SrTiO}_{3}$ (the appearance of $\mathrm{TiO}_{2}$ is a consequence of removing of some Ti atoms from the $B$ sites when doping strontium titanate with nickel).

As concerns to the appearance of the $\mathrm{TiO}_{2}$ phase in the $\mathrm{SrTi}_{0.97} \mathrm{Ni}_{0.03} \mathrm{O}_{3}$ sample annealed at $1100^{\circ} \mathrm{C}$, we suppose that its appearance is possible for kinetic reasons. The formation of the solid solution occurs as a result of a chain of chemical reactions in which the $\mathrm{NiTiO}_{3}$ phase initially formed at $\sim 750^{\circ} \mathrm{C}$ from $\mathrm{NiO}$ and $\mathrm{TiO}_{2}$ reacts with excess $\mathrm{SrO}$ resulted from the thermal decomposition of $\mathrm{SrCO}_{3}$ at $\sim 1000^{\circ} \mathrm{C}$ to produce $\mathrm{SrNiO}_{2.5}+\mathrm{TiO}_{2}$ as intermediate phases. This reaction is quite slow (the preparation of $\mathrm{SrNiO}_{2.5}$ usually takes $48 \mathrm{~h}$ at $1000^{\circ} \mathrm{C}$, Ref. 22). As a result, in the samples annealed at $1100^{\circ} \mathrm{C}$ for $16 \mathrm{~h}$, a mixture of the solid solution, $\mathrm{NiTiO}_{3}$, and $\mathrm{TiO}_{2}$ is observed. At higher annealing temperature, the kinetic processes are faster, the reaction completes, and the composition of the samples is fully controlled by the deviation from stoichiometry.

Therefore, the stable phases in the samples are the singlephase $\mathrm{SrTi}_{1-x} \mathrm{Ni}_{x} \mathrm{O}_{3}$ solid solution and $\mathrm{NiTiO}_{3}$; their ratio depends on the deviation from stoichiometry and the annealing temperature. Nickel cannot be incorporated into the $A$ sites of strontium titanate. The low stability of $\mathrm{Ni}$ at the $A$ site of $\mathrm{SrTiO}_{3}$ is apparently related to the large difference in the ionic radii of $\mathrm{Ni}^{2+}$ and $\mathrm{Sr}^{2+}$. The 12 -fold coordination is not typical for nickel; for the coordination number of 6 , the ionic radius of $\mathrm{Ni}^{2+}(0.69 \AA)$ is much less than that of $\mathrm{Sr}^{2+}$ $(1.18 \AA){ }^{23}$

The XANES data, which were used to determine the oxidation state of nickel, are fully consistent with X-ray and EXAFS data. In the sample with a nominal composition of $\mathrm{Sr}_{0.98} \mathrm{Ni}_{0.02} \mathrm{TiO}_{3}$ annealed at $1500^{\circ} \mathrm{C}$, in which nickel is in the $\mathrm{NiTiO}_{3}$ phase, the oxidation state of $\mathrm{Ni}$ coincides with its oxidation state in $\mathrm{NiO}$ and $\mathrm{NiTiO}_{3}$ and is $2+$. In the singlephase $\mathrm{SrTi}_{0.97} \mathrm{Ni}_{0.03} \mathrm{O}_{3}$ sample annealed at $1500^{\circ} \mathrm{C}$, the shift of the absorption edge with respect to $\mathrm{NiTiO}_{3}$ is maximum and is about twice the shift between the reference compounds $\mathrm{NiTiO}_{3}$ and $\mathrm{BaNiO}_{3-\delta}$. If, following Ref. 21, we start from the number of ions, their nominal charge, and the $\delta \approx 0.4$ value determined from the lattice parameters, the average oxidation state of nickel in $\mathrm{BaNiO}_{3-\delta}$ is $(4-2 \delta) \approx 3.2$. Then, according to the shift of the absorption edge in $\mathrm{SrTi}_{0.97} \mathrm{Ni}_{0.03} \mathrm{O}_{3}$ sample annealed at $1500^{\circ} \mathrm{C}$, the oxidation state of nickel in it should be close to 4+. For the $\mathrm{SrTi}_{0.97} \mathrm{Ni}_{0.03} \mathrm{O}_{3}$ and $\mathrm{Sr}_{0.98} \mathrm{Ni}_{0.02} \mathrm{TiO}_{3}$ samples annealed at $1100^{\circ} \mathrm{C}$, which are the mixture of two nickel-containing 
phases in proportion close to $1: 1$, the position of the absorption edge is intermediate between those in two stable phases and is close to the position of the absorption edge in $\mathrm{BaNiO}_{3-\delta}$ (about 3+).

It should be noted that the question about the oxidation state of $\mathrm{Ni}$ in $\mathrm{SrTi}_{0.97} \mathrm{Ni}_{0.03} \mathrm{O}_{3}$ is not so simple. The discussion about the oxidation state of $\mathrm{Ni}$ in $\mathrm{BaNiO}_{3-\delta}$ is still going on, in particular, the doubts were expressed ${ }^{24}$ about the validity of its formal determination based on the number of ions and their nominal charges. In the cited work, the data of Mössbauer spectroscopy for $\mathrm{BaNiO}_{3}$ indicated the $\mathrm{Ni}$ oxidation state close to $4+$, whereas the photoelectron spectroscopy gave a value close to 3+. The authors of Ref. 24 suggested a model in which $\mathrm{Ni}$ is trivalent and its charge is compensated by a hole bound by one or two negative oxygen ions. Within this model, the $\mathrm{Ni}$ oxidation state determined from the absorption edge shift in our $\mathrm{SrTi}_{0.97} \mathrm{Ni}_{0.03} \mathrm{O}_{3}$ solid solution should be closer to $3+$. This explanation, however, contradicts the fact that our EXAFS data analysis revealed no distortion of the oxygen octahedra, whereas the localization of a hole at one or two oxygen ions should cause its distortion.

At the same time, the experimental study of XANES spectra of $\mathrm{Li}_{x} \mathrm{NiO}_{2}$ compound used in lithium batteries have shown that a variation in the degree of intercalation $x$ changes the $\mathrm{Ni}$ oxidation state from $2+$ to $4+$ and shifts the absorption edge in XANES spectra by $\sim 3.5 \mathrm{eV} .^{25}$ This shift is close to the shift of $2.9 \mathrm{eV}$ observed in our spectra between $\mathrm{NiTiO}_{3}$ and the $\mathrm{SrTi}_{0.97} \mathrm{Ni}_{0.03} \mathrm{O}_{3}$ sample annealed at $1500^{\circ} \mathrm{C}$. Moreover, the interatomic $\mathrm{Ni}-\mathrm{O}$ distance $(1.914 \AA$ ) obtained from our EXAFS measurements is less than the sum of the ionic radii of $\mathrm{Ni}^{3+}$ and $\mathrm{O}^{2-}(0.56+1.4=1.96 \AA)$ and is closer to the sum of the ionic radii of $\mathrm{Ni}^{4+}$ and $\mathrm{O}^{2-}(0.48+1.4=$ $1.88 \AA$ ). Yet another argument in favor of tetravalent nickel can be the small value of the Debye-Waller factor $\sigma_{1}^{2}$, which indicates the absence of the $\mathrm{Ni}$ displacement from the $B$ site in the $\mathrm{SrTi}_{0.97} \mathrm{Ni}_{0.03} \mathrm{O}_{3}$ solid solution. If the nickel atom in this phase was in the $\mathrm{Ni}^{3+}$ oxidation state, it required to be charge-compensated by the oxygen vacancy located nearby the impurity atom (such $\mathrm{Ni}^{3+}-V_{\mathrm{O}}$ axial centers with the $\mathrm{Ni}$ displacement from the center of the octahedron up to $\sim 0.3 \AA$ have been observed in electron spin resonance (ESR) spectra). ${ }^{26,27}$ However, our EXAFS measurements did not reveal noticeable distortion of the oxygen octahedra surrounding the $\mathrm{Ni}$ atom.

It should be noted that the EXAFS data analysis of the $\mathrm{SrTi}_{0.97} \mathrm{Ni}_{0.03} \mathrm{O}_{3}$ sample annealed at $1500^{\circ} \mathrm{C}$ revealed a reduced value of $4.90 \pm 0.34$ for the coordination number for the first shell of Ni. There are two possible explanation of this fact. First, it can be an evidence for the existence of a small amount of $\mathrm{Ni}^{3+}-V_{\mathrm{O}}$ complexes. The coordination number for these complexes is effectively reduced to 4 because one of the oxygen atoms is missing and the other one is located at a different distance compared to four remaining $\mathrm{O}$ atoms and does not contribute much to the EXAFS signal. This explanation agrees with the reduced shift of the absorption edge in our sample with respect to the $\mathrm{Ni}^{4+}$ state in $\mathrm{Li}_{x} \mathrm{NiO}_{2}$. Another explanation is the existence of a small amount of the $\mathrm{NiTiO}_{3}$ phase located at the grain boundaries; the experiment shows that the contamination with this phase strongly decreases the coordination number because of out-of-phase EXAFS oscillations in two nickel-containing phases.

Neverthless, we think that the oxidation state of $\mathrm{Ni}$ at the $B$ site in $\mathrm{SrTiO}_{3}$ is close to $4+$; this disagrees with the suggestion made earlier ${ }^{5,6}$ that $\mathrm{Ni}$ is in the $2+$ oxidation state in the related ferroelectric $\mathrm{PbTiO}_{3}$. Although the question about the actual oxidation state of $\mathrm{Ni}$ in the latter material should be tested experimentally, our findings indicate that the strong light absorption in Ni-doped $\mathrm{SrTiO}_{3}$ is associated with the tetravalent nickel.

From the viewpoint of possible application of doped perovskites in solar energy conversion it is interesting to compare the properties of $\mathrm{SrTiO}_{3}$ doped with nickel and with other $3 d$ elements. ${ }^{13-16}$ The absorption spectra of doped samples are systematically shifted to the infrared region with increasing atomic number from $\mathrm{Mn}$ to $\mathrm{Ni}$ : manganese-doped samples are greenish brown, iron-doped samples are brown, cobalt-doped samples are dark brown, and Ni gives an almost black color to the samples. Thus, for creating samples that strongly absorb light in the whole visible region, the nickel doping seems the most promising. Intense absorption in the samples suggests that it is associated with charge-transfer transitions.

Interestingly, the small value of the Debye-Waller factor for the first shell $\left(\sigma_{1}^{2} \approx 0.0035 \AA^{2}\right)$ also excludes the possibility of Jahn-Teller instability of the $\mathrm{Ni}^{4+}$ ion in $\mathrm{SrTiO}_{3}$, which is possible for the octahedral $d^{6}$ configuration. In $\mathrm{Li}_{x} \mathrm{NiO}_{2}$, the Jahn-Teller instability of $\mathrm{Ni}^{4+}$ manifests itself in the distorted oxygen octahedra with $\mathrm{Ni}-\mathrm{O}$ bond lengths of 1.88 and $2.08 \AA$. In the EXAFS spectra, this distorted environment should be observed as one $\mathrm{O}$ shell with an average interatomic distance of $1.947 \AA$ and a static Debye-Waller factor of $0.009 \AA^{2}$. The experimental value of $\sigma_{1}^{2}$ in $\mathrm{SrTiO}_{3}(\mathrm{Ni})$ is much lower than the value estimated for JahnTeller-distorted environment.

The interpretation of our data on the oxidation state of nickel in $\mathrm{SrTiO}_{3}$ differs much from the results of earlier studies. The comparison with the data of Ref. 28, in which $\mathrm{SrTiO}_{3}(\mathrm{Ni})$ samples were also studied by XAFS technique, shows that the XANES and EXAFS spectra obtained in our work and in Ref. 28 are qualitatively different. For example, in Ref. 28 the shift of the absorption edge in $\mathrm{SrTiO}_{3}(\mathrm{Ni})$ with respect to $\mathrm{NiO}$ was only $1.1 \mathrm{eV}$ (in our samples it is $2.5 \mathrm{eV}$ ). Moreover, even the color of the samples is different (beige in Ref. 28 and almost black in our work). We believe that these differences in the properties of the samples result from the different methods of their preparation (solid-state reaction method in our case and hydrothermal synthesis at $150^{\circ} \mathrm{C}$ in Ref. 28). In Refs. 26 and 27, single crystals of $\mathrm{SrTiO}_{3}(\mathrm{Ni})$ were investigated by electron spin resonance. In these works, the ESR spectra associated with axial $\mathrm{Ni}^{3+}-V_{\mathrm{O}}$ complexes were systematically observed along with the ESR spectra which were attributed to the "cubic" $\mathrm{Ni}^{2+}$ and $\mathrm{Ni}^{3+}$ 
centers. ${ }^{26}$ Unfortunately, no arguments on the basis of which the oxidation state of the $\mathrm{Ni}$ impurity was identified were presented in Ref. 26, and a possible interpretation of the ESR spectra as the spectra of $\mathrm{Ni}^{4+}$ was not discussed.

\section{Conclusion}

The study of Ni-doped $\mathrm{SrTiO}_{3}$ using X-ray diffraction and XAFS spectroscopy enabled to draw the following conclusions:

1. The preparation conditions of single-phase Ni-doped $\mathrm{SrTiO}_{3}$ samples with the impurity concentration up to at least 3\% have been found. When incorporating the impurity into the $A$ sites, the $\mathrm{NiTiO}_{3}$ second phase was precipitated. Regardless of the preparation conditions, the $\mathrm{SrTi}_{1-x} \mathrm{Ni}_{x} \mathrm{O}_{3}$ solid solution and $\mathrm{NiTiO}_{3}$ phase are the most stable phases which can coexist.

2. EXAFS analysis showed that in the single-phase $\mathrm{SrTi}_{0.97} \mathrm{Ni}_{0.03} \mathrm{O}_{3}$ sample, the $\mathrm{Ni}$ atoms substitute for the Ti atoms and are on-center. The distortion of the oxygen octahedra, which could occur because of the Ni off-centering or the existence of the oxygen vacancies in the $\mathrm{Ni}$ environment, was not detected. The reduced value of the coordination number for the first shell was explained by the presence of a small amount of $\mathrm{Ni}^{3+}-V_{\mathrm{O}}$ complexes and the $\mathrm{NiTiO}_{3}$ phase at the grain boundaries.

3. XANES analysis showed that in $\mathrm{NiTiO}_{3}$ the oxidation state of $\mathrm{Ni}$ is $2+$ and in the $\mathrm{SrTi}_{1-x} \mathrm{Ni}_{x} \mathrm{O}_{3}$ solid solution it is close to $4+$.

4. The strongest light absorption in doped samples is associated with the presence of tetravalent nickel in the $\mathrm{SrTi}_{1-x} \mathrm{Ni}_{x} \mathrm{O}_{3}$ solid solution. This doping seems to be the most promising for solar energy converters that exploit the bulk photovoltaic effect.

In the future, we plan to perform similar experiments on the ferroelectric $\mathrm{BaTiO}_{3}$ doped with $3 d$ elements in order to test the feasibility of obtaining the polar material with similar optical and physical properties, in which the bulk photovoltaic effect can be observed for photons in the whole spectrum of solar radiation.

\section{Acknowledgments}

This work was supported by Russian Foundation for Basic Research (Grant No. 13-02-00724). I. A. S. and A. I. L. are grateful to Russian-German laboratory for hospitality and financial support during their stay at BESSY.

\section{References}

${ }^{1}$ B. I. Sturman and V. M. Fridkin, Photogalvanic Effect in Media without the Inversion Center and Related Phenomena (Nauka, Moscow, 1992).
${ }^{2}$ A. M. Glass, D. von der Linde and T. J. Negran, High-voltage bulk photovoltaic effect and the photorefractive process in $\mathrm{LiNbO}_{3}$, Appl. Phys. Lett. 25, 233 (1974).

${ }^{3}$ M. Qin, K. Yao and Y. C. Liang, High efficient photovoltaics in nanoscaled ferroelectric thin films, Appl. Phys. Lett. 93, 122904 (2008).

${ }^{4} \mathrm{M}$. Alexe and D. Hesse, Tip-enhanced photovoltaic effects in bismuth ferrite, Nat. Commun. 2, 256 (2011).

${ }^{5}$ J. W. Bennett, I. Grinberg and A. M. Rappe, New highly polar semiconductor ferroelectrics through $d^{8}$ cation-o vacancy substitution into $\mathrm{PbTiO}_{3}$ : A theoretical study, J. Am. Chem. Soc. 130, 17409 (2008).

${ }^{6}$ G. Y. Gou, J. W. Bennett, H. Takenaka and A. M. Rappe, Post density functional theoretical studies of highly polar semiconductive $\mathrm{Pb}\left(\mathrm{Ti}_{1-x} \mathrm{Ni}_{x}\right) \mathrm{O}_{3-x}$ solid solutions: Effects of cation arrangement on band gap, Phys. Rev. B 83, 205115 (2011).

${ }^{7}$ Y. Inaguma, M. Yoshida, T. Tsuchiya, A. Aimi, K. Tanaka, T. Katsumata and D. Mori, High-pressure synthesis of novel lithium niobate-type oxides, J. Phys.: Conf. Ser. 215, 012131 (2010).

${ }^{8}$ Y. Inaguma, K. Tanaka, T. Tsuchiya, D. Mori, T. Katsumata, T. Ohba, K.-I. Hiraki, T. Takahashi and H. Saitoh, Synthesis, structural transformation, thermal stability, valence state, and magnetic and electronic properties of $\mathrm{PbNiO}_{3}$ with perovskite- and $\mathrm{LiNbO}_{3}$ type structures, J. Am. Chem. Soc. 133, 16920 (2011).

${ }^{9}$ X. F. Hao, A. Stroppa, S. Picozzi, A. Filippetti and C. Franchini, Exceptionally large room-temperature ferroelectric polarization in the $\mathrm{PbNiO}_{3}$ multiferroic nickelate: First-principles study, Phys. Rev. B 86, 014116 (2012).

${ }^{10}$ M. Azuma, S. Carlsson, J. Rodgers, M. G. Tucker, M. Tsujimoto, S. Ishiwata, S. Isoda, Y. Shimakawa, M. Takano and J. P. Attfield, Pressure-induced intermetallic valence transition in $\mathrm{BiNiO}_{3}, J$. Am. Chem. Soc. 129, 14433 (2007).

${ }^{11}$ V. V. Shvartsman, S. Bedanta, P. Borisov, W. Kleemann, A. Tkach and $\mathrm{P}$. M. Vilarinho, $(\mathrm{Sr}, \mathrm{Mn}) \mathrm{TiO}_{3}$ : A magnetoelectric multiglass, Phys. Rev. Lett. 101, 165704 (2008).

${ }^{12}$ W. Kleemann, S. Bedanta, P. Borisov, V. V. Shvartsman, S. Miga, J. Dec, A. Tkach and P. M. Vilarinho, Multiglass order and magnetoelectricity in $\mathrm{Mn}^{2+}$ doped incipient ferroelectrics, Eur. Phys. J. B 71, 407 (2009).

${ }^{13}$ A. I. Lebedev, I. A. Sluchinskaya, A. Erko and V. F. Kozlovskii, Direct evidence for off-centering of $\mathrm{Mn}$ impurity in $\mathrm{SrTiO}_{3}, J E T P$ Lett. 89, 457 (2009).

${ }^{14}$ I. A. Sluchinskaya, A. I. Lebedev and A. Erko, Local environment and oxidation state of a $\mathrm{Mn}$ impurity in $\mathrm{SrTiO}_{3}$ determined from XAFS data, Bull. Russ. Acad. Sci.: Phys. 74, 1235 (2010).

${ }^{15}$ I. A. Sluchinskaya, A. I. Lebedev and A. Erko. The 19th AllRussian Conf. Physics of Ferroelectrics, Moscow (2011), Abstract book (2011), p. 116.

${ }^{16}$ I. A. Sluchinskaya, A. I. Lebedev, V. F. Kozlovskii and A. Erko, The 8th National Conf. " $X$-ray, synchrotron radiation, neutrons, and electrons for studying nanosystems and materials", Moscow (2011), Abstract book (2011), p. 347.

${ }^{17}$ A. I. Lebedev, I. A. Sluchinskaya, V. N. Demin and I. Munro, EXAFS studies of of the influence of impurities on the phase transition in GeTe, Izv. Akad. Nauk SSSR, Ser. Fiz. 60, 46 (1996).

${ }^{18}$ A. I. Lebedev, I. A. Sluchinskaya, V. N. Demin and I. H. Munro, Off-centering of $\mathrm{Pb}$ and $\mathrm{Sn}$ impurities in GeTe, Phys. Rev. B 55, 14770 (1997). 
${ }^{19} \mathrm{FEFF}$ project home page, http://leonardo.phys.washington.edu/ feff/. URL http://leonardo.phys.washington.edu/feff/.

${ }^{20}$ IFEFFIT project home page, http://cars9.uchicago.edu/ifeffit/. URL http://cars9.uchicago.edu/ifeffit/.

${ }^{21}$ M. Arjomand and D. J. Machin, Oxide chemistry. Part I. Ternary oxides containing nickel in oxidation states II, III, and IV, $J$. Chem. Soc., Dalton Trans., 1055 (1975).

${ }^{22}$ Y. Takeda, T. Hashino, H. Miyamoto, F. Kanamaru, S. Kume and M. Koizumi, Synthesis of $\mathrm{SrNiO}_{3}$ and related compound, $\mathrm{Sr}_{2} \mathrm{Ni}_{2} \mathrm{O}_{5}$, J. Inorg. Nucl. Chem. 34, 1599 (1972).

${ }^{23}$ R. D. Shannon, Revised effective ionic radii and systematic studies of interatomic distances in halides and chalcogenides, Acta Cryst. A 32, 751 (1976).

${ }^{24}$ R. Gottschall, R. Schöllhorn, M. Muhler, N. Jansen, D. Walcher and P. Gütlich, Electronic state of nickel in barium nickel oxide, $\mathrm{BaNiO}_{3}$, Inorg. Chem. 37, 1513 (1998).
${ }^{25}$ A. N. Mansour and C. A. Melendres, Analysis of X-ray absorption spectra of some nickel oxycompounds using theoretical standards, J. Phys. Chem. A 102, 65 (1998).

${ }^{26}$ K. A. Müller, W. Berlinger and R. S. Rubins, Observation of two charged states of a nickel-oxygen vacancy pair in $\mathrm{SrTiO}_{3}$ by paramagnetic resonance, Phys. Rev. 186, 361 (1969).

${ }^{27}$ S.-Y. Wu, J.-Z. Lin, Q. Fu and H.-M. Zhang, Investigations on the impurity displacements and the $g$ factors of the two tetragonal $\mathrm{Ni}^{3+}$ centres in $\mathrm{SrTiO}_{3}$, Phys. Scripta. 75, 147 (2007).

${ }^{28}$ A. M. Beale, M. Paul, G. Sankar, R. J. Oldman, C. R. A. Catlow, S. French and M. Fowles, Combined experimental and computational modelling studies of the solubility of nickel in strontium titanate, J. Mater. Chem. 19, 4391 (2009). 